Cite this: J. Mater. Chem. C, 2014, 2, 3732

Received 19th December 2013 Accepted 24th February 2014

DOI: $10.1039 /$ c3tc32513j

www.rsc.org/MaterialsC

\section{Tungstate nanosheet ink as a photonless and electroless chromic device $\uparrow$}

\author{
Masahiro Miyauchi, ${ }^{\text {*ab }}$ Akihiko Kondo, ${ }^{a}$ Daiki Atarashi ${ }^{a}$ and Etsuo Sakai ${ }^{a}$ \\ Cesium tungstate $\left(\mathrm{Cs}_{4} \mathrm{~W}_{11} \mathrm{O}_{36}{ }^{2-}\right)$ nanosheets coated on an aluminum (Al) substrate turned blue in an \\ aqueous solution, acting as an ink, and rapidly decolorized under air exposure, acting as an eraser. The \\ decoloration rate of $\mathrm{Cs}_{4} \mathrm{~W}_{11} \mathrm{O}_{36}{ }^{2-}$ nanosheets was several orders of magnitude more efficient than that \\ of conventional tungsten trioxide $\left(\mathrm{WO}_{3}\right)$ particles, owing to efficient electron transfer in the nanosheet \\ structure.
}

\section{Introduction}

Chromism is a process that causes a reversible color change in materials in response to an external stimulus and is useful for various industrial applications, such as displays, sensors, and data storage devices. Photochromism and electrochromism are transformations that are induced by stimulation with light irradiation and an electric field, respectively. ${ }^{1-4}$ Among chromic materials, tungsten trioxide $\left(\mathrm{WO}_{3}\right)$ exhibits efficient photochromic and electrochromic property reactivity. ${ }^{5-8}$ However, during the coloration of $\mathrm{WO}_{3}$ under light irradiation, electrons are trapped at deep levels, and the rate of the decoloration process is very slow in air. ${ }^{9}$ As an electrochromic material, $\mathrm{WO}_{3}$ requires complicated apparatus and an electrode structure, including an electric power supply and a complicated sandwichtype cell with a transparent electroconductive substrate, such as indium-tin-oxide (ITO), and a counter electrode filled with an electrolyte solution., ${ }^{2,4}$

Recently, we reported that a $\mathrm{WO}_{3}$-based chromic device is capable of functioning without light irradiation or an electric power supply. ${ }^{10}$ The $\mathrm{WO}_{3}$-coated aluminum (Al) substrate turns a dark color upon exposure to an aqueous solution, with subsequent exposure to oxygen restoring the original lightyellow color of the material. Although this phenomenon is similar to solvatochromism in organic chromophore molecules, ${ }^{11}$ the color change in $\mathrm{WO}_{3} / \mathrm{Al}$ is due to the galvanic potential between $\mathrm{WO}_{3}$ and $\mathrm{Al}$, rather than as a result of the polarity of the solvent. This $\mathrm{WO}_{3}$ based chromic device exhibits high stability against thermal or chemical treatment rather than a solvatochromic device using organic chromophore molecules.

${ }^{a}$ Graduate School of Science and Engineering, Tokyo Institute of Technology, 2-12-1 Ookayama, Meguro-ku, Tokyo 152-8552, Japan. E-mail: mmiyauchi@ceram.titech. ac.jp; Fax: +8135734 3368; Tel: +81357342527

${ }^{b}$ PRESTO, JST, 4-1-8 Honcho, Kawaguchi, Saitama 332-0012, Japan

$\dagger$ Electronic supplementary information (ESI) available: UV-vis spectra recorded in reflection mode, photos of films for various thicknesses, and decay in color under alkaline conditions. See DOI: 10.1039/c3tc32513j
Herein, we developed an efficient galvanic chromic device composed of a film of layered cesium tungstate $\left(\mathrm{Cs}_{4} \mathrm{~W}_{11} \mathrm{O}_{36}{ }^{2-}\right)$ nanosheets, which are transparent in the visible-light range due to the quantum confinement effect. $\mathrm{Cs}_{4} \mathrm{~W}_{11} \mathrm{O}_{36}{ }^{2-}$ nanosheets coated on an aluminum ( $\mathrm{Al})$ substrate exhibited a rapid, reversible color change. $\mathrm{Cs}_{4} \mathrm{~W}_{11} \mathrm{O}_{36}{ }^{2-} / \mathrm{Al}$ turned blue in an aqueous acid solution, and rapidly decolorized under air exposure. In this device, the aqueous solvent acts as an ink, while oxygen exposure acts as an eraser. The color change was due to the galvanic potential between $\mathrm{Cs}_{4} \mathrm{~W}_{11} \mathrm{O}_{36}{ }^{2-}$ and $\mathrm{Al}$, and the decoloration rate of $\mathrm{Cs}_{4} \mathrm{~W}_{11} \mathrm{O}_{36}{ }^{2-}$ is 25-fold higher than that of $\mathrm{WO}_{3}$ particles. The efficient color change is due to the nanostructure of the $\mathrm{Cs}_{4} \mathrm{~W}_{11} \mathrm{O}_{36}{ }^{2-}$ nanosheets, which promotes effective electron transfer. Thus, the sheet-like structure of $\mathrm{Cs}_{4} \mathrm{~W}_{11} \mathrm{O}_{36}{ }^{2-}$ has suitable properties for constructing a highperformance chromic device.

\section{Experimental}

\subsection{Synthesis of cesium tungstate $\left(\mathrm{Cs}_{4} \mathrm{~W}_{11} \mathrm{O}_{36}{ }^{2-}\right)$ nanosheets}

Layered $\mathrm{Cs}_{4} \mathrm{~W}_{11} \mathrm{O}_{36}{ }^{2-}$ nanosheets were exfoliated from bulk $\mathrm{Cs}_{6} \mathrm{~W}_{11} \mathrm{O}_{36}$ by a chemical treatment, referring to the previous report. ${ }^{12}$ Powder forms of $\mathrm{Cs}_{2} \mathrm{CO}_{3}$ and $\mathrm{WO}_{3}$ were mixed at a molar ratio of $3: 11$ and then ground to a fine powder with a mortar and pestle. The mixed powder was calcined at $1173 \mathrm{~K}$ for $6 \mathrm{~h}$. After annealing, the resulting dark blue solid $\left(\mathrm{Cs}_{6} \mathrm{~W}_{11} \mathrm{O}_{36}\right)$ was ground to powder and $0.500 \mathrm{~g}$ of the powder was suspended in $50 \mathrm{~mL}$ of a $12 \mathrm{M}$ hydrogen chloride $(\mathrm{HCl})$ solution. After stirring the solution for $24 \mathrm{~h}$ at room temperature, the solution was centrifuged at $3000 \mathrm{rpm}$ for $10 \mathrm{~min}$ and the acidic supernatant was discarded. Fifty milliliters of a $12 \mathrm{M} \mathrm{HCl}$ solution was then added and the suspension was again stirred for $24 \mathrm{~h}$. The solution was centrifuged at $3000 \mathrm{rpm}$ for $10 \mathrm{~min}$ and the formed yellow precipitate (protonated cesium tungstate; $\mathrm{H}_{2} \mathrm{Cs}_{4} \mathrm{~W}_{11} \mathrm{O}_{36}$ ) was washed six times with pure water. The precipitate was dispersed in $50 \mathrm{~mL}$ of an aqueous tetra(n-butyl) ammonium hydroxide (TBAOH; Aldrich Ltd.) solution to 
achieve neutral conditions. This suspension was shaken for 10 days at room temperature yielding a colloidal suspension with a milky appearance. For comparison, commercial $\mathrm{WO}_{3}$ colloidal solution (Sekisui-Jushi Ltd.) was used in the present study as a conventional chromic material.

\subsection{Thin film fabrication of $\mathrm{Cs}_{4} \mathrm{~W}_{11} \mathrm{O}_{36}{ }^{2-}$ nanosheets on an aluminum substrate}

An aluminum (Al) substrate $(1 \mathrm{~cm} \times 1 \mathrm{~cm} \times 1 \mathrm{~mm})$ was washed by ultrasonication in ethanol for $10 \mathrm{~min}$ and surface contaminants were removed by UV-ozone treatment for $30 \mathrm{~min}$. A colloidal suspension of $\mathrm{Cs}_{4} \mathrm{~W}_{11} \mathrm{O}_{36}{ }^{2-}$ nanosheets was coated on the Al substrate using a dipping method. The samples were then dried in air at room temperature. For comparison, we prepared a $\mathrm{WO}_{3}$ particle-coated $\mathrm{Al}$ substrate by spin-coating of commercial $\mathrm{WO}_{3}$ colloidal solution. ${ }^{10}$

\subsection{Measurement and analysis}

Transmission electron microscopy (TEM; model JEM-2010, JEOL Instruments, Japan) was used to observe the structure of $\mathrm{Cs}_{4} \mathrm{~W}_{11} \mathrm{O}_{36}{ }^{2-}$ nanosheets using an acceleration voltage of $200 \mathrm{kV}$. X-ray photoelectron spectroscopy (XPS; model ESCA5500MT, Perkin Elmer Instruments, Japan) analysis was conducted to determine the chemical states of cesium tungstate using standard $\mathrm{Mg} \mathrm{K} \alpha \mathrm{X}$-rays. Cross-sectional images of the thin films were observed using scanning electron microscopy (SEM; model S-4500, Hitachi Co., Tokyo Japan). Surface morphologies of the mono-layered nanosheet film on the mica substrate were observed by atomic force microscopy (AFM; model SPM-9700, Shimadzu Instruments, Japan). AFM measurements were performed in the tapping mode under ambient conditions. Absorption spectra of the $\mathrm{Cs}_{4} \mathrm{~W}_{11} \mathrm{O}_{36}{ }^{2-} / \mathrm{Al}$ and $\mathrm{WO}_{3} / \mathrm{Al}$ samples were recorded using a spectrophotometer (UV-vis, model V-660, Jasco Instruments, Japan) by a diffuse-reflectance method with $\mathrm{BaSO}_{4}$ as background. Powder X-ray diffraction (XRD) patterns were recorded with a diffractometer (model SmartLab, Rigaku Instruments, Japan) using $\mathrm{Cu} \mathrm{K} \alpha$ radiation $(\lambda=0.15405 \mathrm{~nm})$. Furthermore, XRD patterns of the thin films were recorded using out-of-plane and in-plane methods. Coloration was evaluated after dipping the films in an aqueous $\mathrm{HCl}$ solution $\mathrm{pH}$ 2.0) for 5 min using a spectrophotometer as described above.

\section{Results and discussion}

Layered $\mathrm{Cs}_{4} \mathrm{~W}_{11} \mathrm{O}_{36}{ }^{2-}$ nanosheets were exfoliated from bulk $\mathrm{Cs}_{6} \mathrm{~W}_{11} \mathrm{O}_{36}$ by a chemical treatment, according to a previous paper. ${ }^{12}$ In the present study, we optimized the ratio of the $\mathrm{Cs}_{2} \mathrm{CO}_{3}$ and $\mathrm{WO}_{3}$ starting materials to achieve a high production yield of the $\mathrm{Cs}_{6} \mathrm{~W}_{11} \mathrm{O}_{36}$ crystal structure. Fig. 1(a) shows the XRD pattern of the calcined powder when the molar ratio of Cs/ $\mathrm{W}$ in the starting materials was $8 / 11$, which is the same condition as described in a previous report. ${ }^{12}$ However, all XRD peaks were assigned to $\mathrm{CsW}_{2} \mathrm{O}_{6}$, which was not a layered structure but formed a three-dimensional tunnel structure. In the present study, the ratio of the starting materials was optimized as $\mathrm{Cs} / \mathrm{W}=6 / 11$ to achieve a high production yield of the layered

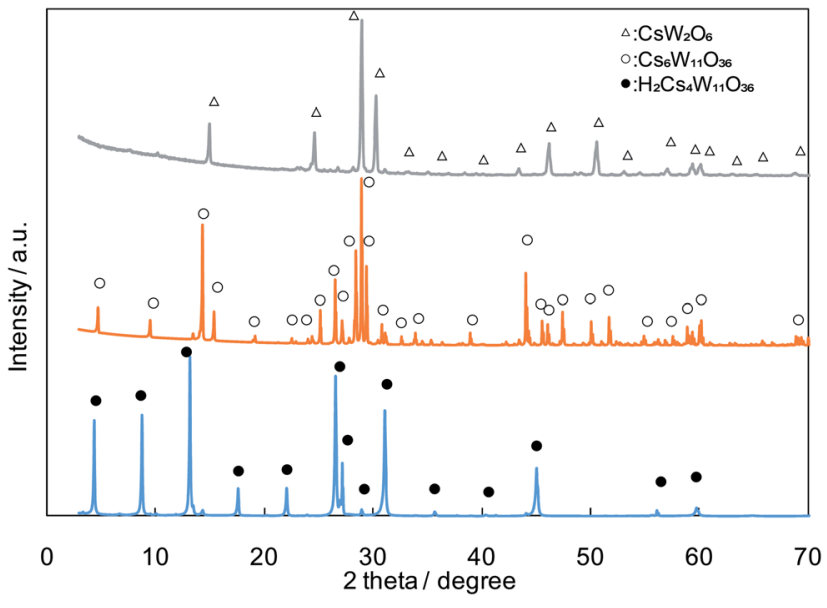

Fig. 1 XRD patterns of the powder forms of: (a) bulk $\mathrm{CsW}_{2} \mathrm{O}_{6}$, (b) layered $\mathrm{Cs}_{6} \mathrm{~W}_{11} \mathrm{O}_{36}$, and (c) protonated layered $\mathrm{H}_{2} \mathrm{Cs}_{4} \mathrm{~W}_{11} \mathrm{O}_{36}$.

$\mathrm{Cs}_{6} \mathrm{~W}_{11} \mathrm{O}_{36}$ structure. The XRD pattern of $\mathrm{Cs}_{6} \mathrm{~W}_{11} \mathrm{O}_{36}$ synthesized in the present work is shown in Fig. 1(b). Fig. 1(c) shows the XRD pattern of protonated cesium tungstate $\left(\mathrm{H}_{2} \mathrm{Cs}_{4} \mathrm{~W}_{11} \mathrm{O}_{36}\right)$.

Fig. 2(a) shows photographs of aggregates of bulk $\mathrm{Cs}_{6} \mathrm{~W}_{11} \mathrm{O}_{36}$ and protonated $\mathrm{H}_{2} \mathrm{Cs}_{4} \mathrm{~W}_{11} \mathrm{O}_{36}$ resuspended in water, and $\mathrm{Cs}_{4} \mathrm{~W}_{11} \mathrm{O}_{36}{ }^{2-}$ nanosheets in water $\left(\mathrm{pH}\right.$ 7). As $\mathrm{Cs}_{4} \mathrm{~W}_{11} \mathrm{O}_{36}{ }^{2-}$ nanosheets have an anionic surface they are highly dispersed in water even under neutral conditions. TEM analysis revealed that bulk $\mathrm{Cs}_{4} \mathrm{~W}_{11} \mathrm{O}_{36}{ }^{2-}$ was efficiently exfoliated and formed a sheetlike structure in water. The line profile obtained from an atomic force microscopy (AFM) image indicated that the thickness of the $\mathrm{Cs}_{4} \mathrm{~W}_{11} \mathrm{O}_{36}{ }^{2-}$ nanosheet was about $2.3 \mathrm{~nm}$ (Fig. 2(c)), which is consistent with the reported thickness of a monolayer of a $\mathrm{Cs}_{4} \mathrm{~W}_{11} \mathrm{O}_{36}{ }^{2-}$ nanosheet. ${ }^{12} \mathrm{~A}$ colloidal suspension of $\mathrm{Cs}_{4} \mathrm{~W}_{11} \mathrm{O}_{36}{ }^{2-}$ nanosheets was coated on an $\mathrm{Al}$ substrate (a)
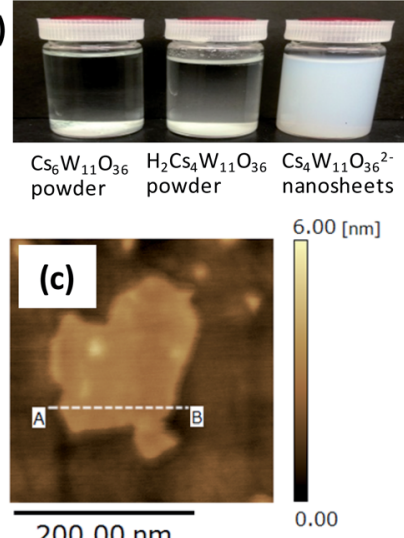

$200.00 \mathrm{~nm}$

A-B 2.50

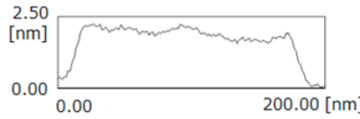

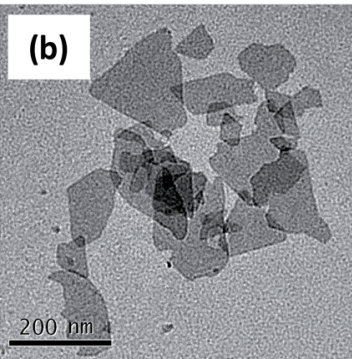

(d)

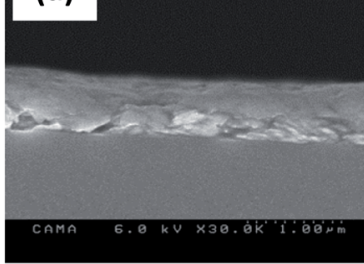

Fig. 2 Photographs of colloidal solutions of $\mathrm{Cs}_{6} \mathrm{~W}_{11} \mathrm{O}_{36}$ and $\mathrm{H}_{2} \mathrm{Cs}_{4} \mathrm{~W}_{11} \mathrm{O}_{36}$ powders, and $\mathrm{Cs}_{4} \mathrm{~W}_{11} \mathrm{O}_{36}{ }^{2-}$ nanosheets (a). TEM (b) and AFM (c) images of $\mathrm{Cs}_{4} \mathrm{~W}_{11} \mathrm{O}_{36}{ }^{2-}$ nanosheets. The AFM line profile of the $\mathrm{Cs}_{4} \mathrm{~W}_{11} \mathrm{O}_{36}{ }^{2-}$ nanosheet is shown below the AFM image. The crosssectional SEM image of a thin film of $\mathrm{Cs}_{4} \mathrm{~W}_{11} \mathrm{O}_{36}{ }^{2-}$ nanosheets (d). 
using a dipping method. A cross-sectional scanning electron microscopy (SEM) image of the coated $\mathrm{Al}$ substrate is shown in Fig. 2(d). The thickness of the $\mathrm{Cs}_{4} \mathrm{~W}_{11} \mathrm{O}_{36}{ }^{2-}$ nanosheet layer could be controlled by adjusting the concentration of the colloidal suspension and the dipping duration. The thickness of $\mathrm{Cs}_{4} \mathrm{~W}_{11} \mathrm{O}_{36}{ }^{2-}$ nanosheet films was adjusted to $\sim 500 \mathrm{~nm}$ by considering the depth of the space charge layer as discussed below.

In-plane and out-of-plane X-ray diffraction (XRD) patterns of the $\mathrm{Cs}_{4} \mathrm{~W}_{11} \mathrm{O}_{36}{ }^{2-}$ nanosheet films are shown in Fig. 3. Peaks observed in the out-of-plane pattern were assigned to the $c$-axis of the exfoliated $\mathrm{Cs}_{4} \mathrm{~W}_{11} \mathrm{O}_{36}{ }^{2-}$ plane, while peaks detected in the in-plane pattern were perpendicular to the $c$-axis. These results indicate that the exfoliated $c$-plane of $\mathrm{Cs}_{4} \mathrm{~W}_{11} \mathrm{O}_{36}{ }^{2-}$ nanosheets is attached to the substrate and that the thin film is highly oriented in the direction of the $c$-axis, which is perpendicular to the Al substrate.

Structural analysis of the commercial $\mathrm{WO}_{3}$ particles as a comparison sample was conducted and the results are shown in Fig. 4. The thickness of the commercial $\mathrm{WO}_{3}$ film was similar to that of the $\mathrm{Cs}_{4} \mathrm{~W}_{11} \mathrm{O}_{36}{ }^{2-}$ nanosheet film (about $500 \mathrm{~nm}$ ). The XRD pattern of the commercial $\mathrm{WO}_{3}$ revealed that its crystal phase displayed a monoclinic $\mathrm{WO}_{3}$ structure, and that of the $\mathrm{WO}_{3}$ film was polycrystalline without any crystal orientation.

Fig. 5(a) shows UV-vis absorption spectra recorded by a diffuse reflectance method for the $\mathrm{WO}_{3}$ and $\mathrm{Cs}_{4} \mathrm{~W}_{11} \mathrm{O}_{36}{ }^{2-}$ thin films. Before being immersed in aqueous solution, the $\mathrm{WO}_{3}$ thin film exhibited optical absorption below $460 \mathrm{~nm}$ under atmospheric conditions, a property that is consistent with the band-gap of $\mathrm{WO}_{3}$. In contrast, the absorption edge of the $\mathrm{Cs}_{4} \mathrm{~W}_{11} \mathrm{O}_{36}{ }^{2-}$ film was observed around $350 \mathrm{~nm}$. These results demonstrate that $\mathrm{Cs}_{4} \mathrm{~W}_{11} \mathrm{O}_{36}{ }^{2-}$ nanosheets have a wider band gap than that of $\mathrm{WO}_{3}$ particles, owing to the quantum confinement effect of the nanosheet structure. For this reason, the $\mathrm{Cs}_{4} \mathrm{~W}_{11} \mathrm{O}_{36}{ }^{2-}$ nanosheet film appeared transparent, whereas the film of $\mathrm{WO}_{3}$ particles was yellow. However, after dipping the $\mathrm{Cs}_{4} \mathrm{~W}_{11} \mathrm{O}_{36}{ }^{2-}$ nanosheet and $\mathrm{WO}_{3}$ films in an aqueous acid solution with a pH value of 2.0 for $2 \mathrm{~min}$, both films turned blue.

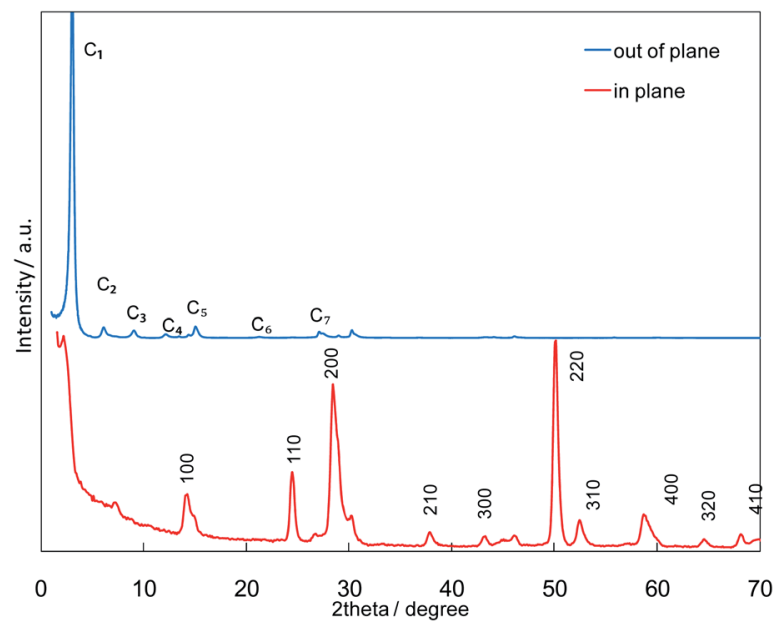

Fig. 3 XRD patterns for a thin film of $\mathrm{Cs}_{4} \mathrm{~W}_{11} \mathrm{O}_{36}{ }^{2-}$ nanosheets. Outof-plane and in-plane XRD measurements are shown.

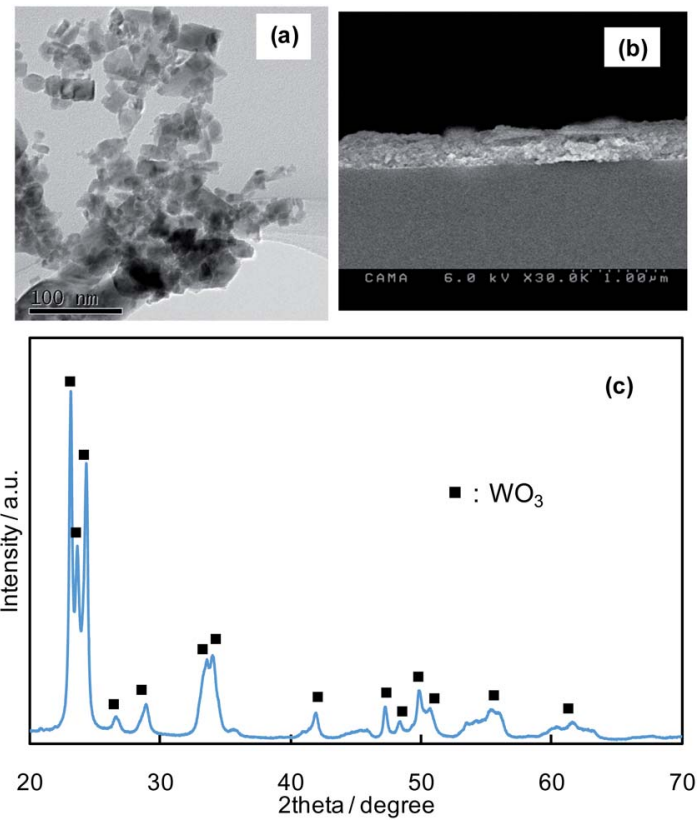

Fig. 4 TEM image of commercial $\mathrm{WO}_{3}$ particles (a), cross-sectional SEM image of the commercial $\mathrm{WO}_{3}$-coated thin film (b), and out-ofplane XRD pattern of the thin film of commercial $\mathrm{WO}_{3}$ (c).
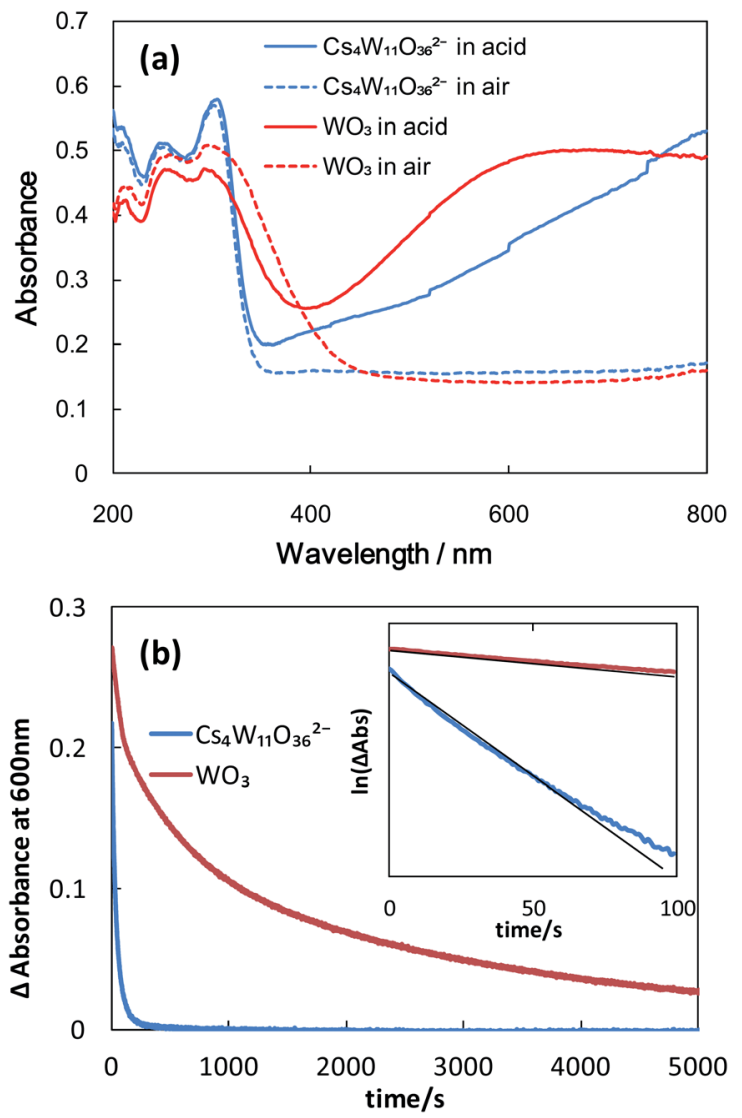

Fig. 5 UV-vis spectra for thin films before and after acid treatment (a). Decay in color (at $600 \mathrm{~nm}$ ) for thin films in air (b). The inset of (b) shows the relationship between natural logarithm and time. 
This coloration effect was induced by the injection of electrons from the $\mathrm{Al}$ substrate to the $\mathrm{Cs}_{4} \mathrm{~W}_{11} \mathrm{O}_{36}{ }^{2-}$ nanosheets or $\mathrm{WO}_{3}$ particles, leading to the reduction of $\mathrm{W}^{6+}$ to $\mathrm{W}^{5+}$. Simultaneously with the reduction reaction, protons are injected into the $\mathrm{Cs}_{4} \mathrm{~W}_{11} \mathrm{O}_{36}{ }^{2-}$ and $\mathrm{WO}_{3}$ crystals. ${ }^{13,14}$ Under these conditions, a broad absorption peak around $650 \mathrm{~nm}$ was observed for the $\mathrm{WO}_{3}$ film, whereas the $\mathrm{Cs}_{4} \mathrm{~W}_{11} \mathrm{O}_{36}{ }^{2-}$ nanosheet film absorbed more photons near the infrared region around $800 \mathrm{~nm}$ rather than the $\mathrm{WO}_{3}$ film (Fig. 5(a)). These results indicate that the potential energy of trapped electrons in $\mathrm{Cs}_{4} \mathrm{~W}_{11} \mathrm{O}_{36}{ }^{2-}$ nanosheets is lower than that of the electrons in $\mathrm{WO}_{3}$ films. We also evaluated the absorption spectra of thin films in a reflectance mode without using an integration sphere unit and could see the obvious color change even in a reflectance mode (see ESI, Fig. $\mathrm{S} 1 \dagger$ ).

After exposure to air, the blue substrates returned to their initial color, because the trapped electrons in $\mathrm{W}^{5+}$ species reduce oxygen molecules in air. Fig. 5(b) shows the changes in the absorbance value at $600 \mathrm{~nm}$ for the decoloration process under air exposure. Notably, the rate of decoloration of the $\mathrm{Cs}_{4} \mathrm{~W}_{11} \mathrm{O}_{36}{ }^{2-}$ nanosheet film is markedly faster than that of the $\mathrm{WO}_{3}$ film. A plot of the relationship between the natural logarithm of absorbance and time shows that the decay follows a linear trajectory (Fig. 5(b), inset). These results indicate that the decoloration process follows first-order kinetics, a finding that is consistent with the photochromic decoloration process in $\mathrm{WO}_{3} \cdot{ }^{15}$ The half-life for the decoloration of $\mathrm{Cs}_{4} \mathrm{~W}_{11} \mathrm{O}_{36}{ }^{2-}$ nanosheets was $25 \mathrm{~s}$, which was 25 -fold more efficient than that of $\mathrm{WO}_{3}$ particles (650 s).

The Al substrate can be generally oxidized under anodic polarization by an electric field more positive than its redox potential $(+1.662 \mathrm{~V} v$ s. $\mathrm{NHE})$. In contrast, $\mathrm{Cs}_{4} \mathrm{~W}_{11} \mathrm{O}_{36}{ }^{2-}$ and $\mathrm{WO}_{3}$ are reduced under cathodic polarization at a potential more negative than their flat-band potentials. When a thin film of a metal oxide semiconductor is coated on an $\mathrm{Al}$ substrate, a galvanic potential is generated between the film and the substrate. As the galvanic potential is the driving force that initiates the coloration reaction, the thickness of the semiconductor film should be less than that of the space charge layer between the metal substrate and the semiconductor film. We investigated the thickness dependence of the coloring phenomena. When the thickness of the tungstate nanosheet was more than two micrometers, the color of this film became inhomogeneous and blue spots were observed around pinholes and cracks of thin films (see ESI, Fig. S2 $\dagger$ ). In contrast, the color was homogeneous, when the thickness was $500 \mathrm{~nm}$. These results indicate that the thickness for homogeneous coloration should be less than several hundred nanometers. The distance of the space charge layer has been estimated by using Poisson's equation, and the estimated distance of the space charge layer in the present study is about several micrometers by using a reasonable carrier density of $10^{16} \mathrm{~cm}^{-3}$ for undoped metal oxide. Our $\mathrm{Cs}_{4} \mathrm{~W}_{11} \mathrm{O}_{36}{ }^{2-}$ and $\mathrm{WO}_{3}$ films were insulative before coloration, thus the thickness of our film should be less than several micrometers for coloration. Furthermore, the thinner film is better for the diffusion of electrons. But when the thickness of cesium tungstate is too thin, visible light absorption in the thin film is not so large and coloration is not obvious.
Therefore, the thickness of cesium tungstate nanosheet films in the present study has been adjusted to $\sim 500 \mathrm{~nm}$.

In the chromic devices synthesized here, $\mathrm{Cs}_{4} \mathrm{~W}_{11} \mathrm{O}_{36}{ }^{2-}$ or $\mathrm{WO}_{3}$ is reduced in an acid solution to form color centers, particularly $\mathrm{W}^{5+}$, together with the intercalation of protons in the crystal lattice, ${ }^{\mathbf{1 6}}$ whereas $\mathrm{Al}$ is oxidized to form $\mathrm{Al}^{3+}$ ions, which dissolve into the aqueous acid solution. Fig. 6 shows XPS spectra of the $\mathrm{W}-4 \mathrm{f}$ orbital before and after coloration of the thin film of the $\mathrm{Cs}_{4} \mathrm{~W}_{11} \mathrm{O}_{36}{ }^{2-}$ nanosheet. The shape of the XPS curve before acid treatment was deconvoluted into two doublets, where the main doublet at $36.0 \mathrm{eV}$ could be assigned to a $\mathrm{W}-4 \mathrm{f}_{7 / 2}$ orbital and the other doublet at $38.1 \mathrm{eV}$ was due to $\mathrm{W}-4 \mathrm{f}_{5 / 2}$, corresponding to the $\mathrm{W}^{6+}$ oxidation state. As shown in Fig. 6(b), a second doublet appeared after acid treatment at lower binding energies of 34.2 and $36.3 \mathrm{eV}$, which were assigned to $\mathrm{W}-4 \mathrm{f}_{7 / 2}$ and $4 \mathrm{f}_{5 / 2}$, respectively, and corresponded to the $\mathrm{W}^{5+}$ oxidation state. These results revealed the formation of $\mathrm{W}^{5+}$ species after dipping the $\mathrm{Cs}_{4} \mathrm{~W}_{11} \mathrm{O}_{36}{ }^{2-}$ nanosheet into aqueous solution. The percentage of $\mathrm{W}^{5+}$ after acid treatment was $21.4 \%$.

In the decoloration process, reduced tungsten species are oxidized and return to their initial color upon exposure to oxygen. Specifically, electrons trapped in tungsten ions in the crystal lattice diffuse to the nanosheet surface where they react with oxygen molecules in air, reconverting the color of the tungsten species to their initial states. As shown in Fig. 5(a), the potential energy of trapped electrons in $\mathrm{Cs}_{4} \mathrm{~W}_{11} \mathrm{O}_{36}{ }^{2-}$ is lower than that of trapped electrons in $\mathrm{WO}_{3}$, indicating that electrons in $\mathrm{Cs}_{4} \mathrm{~W}_{11} \mathrm{O}_{36}{ }^{2-}$ have higher reduction potential. Furthermore, the diffusion length of trapped electrons in $\mathrm{Cs}_{4} \mathrm{~W}_{11} \mathrm{O}_{36}{ }^{2-}$ is much shorter than that of $\mathrm{WO}_{3}$ particles, as the thickness of $\mathrm{Cs}_{4} \mathrm{~W}_{11} \mathrm{O}_{36}{ }^{2-}$ nanosheets $(2.3 \mathrm{~nm})$ is markedly smaller than the diameter of $\mathrm{WO}_{3}$ particles (several tens of $\mathrm{nm}$ ). Thus, the high coloration efficiency observed for $\mathrm{Cs}_{4} \mathrm{~W}_{11} \mathrm{O}_{36}{ }^{2-}$ nanosheets is due to efficient electron transfer within the sheet-like nanostructure of this material. The plausible scheme for the reversible color change is shown in Fig. 7.

The repeatability of coloration and decoloration processes is important for practical applications. Fig. 8 shows the repeatability of the reversible color change in the $\mathrm{Cs}_{4} \mathrm{~W}_{11} \mathrm{O}_{36}{ }^{2} / \mathrm{Al}$ film upon alternating exposure to acid and ambient air. We confirmed that coloration and decoloration could be repeated
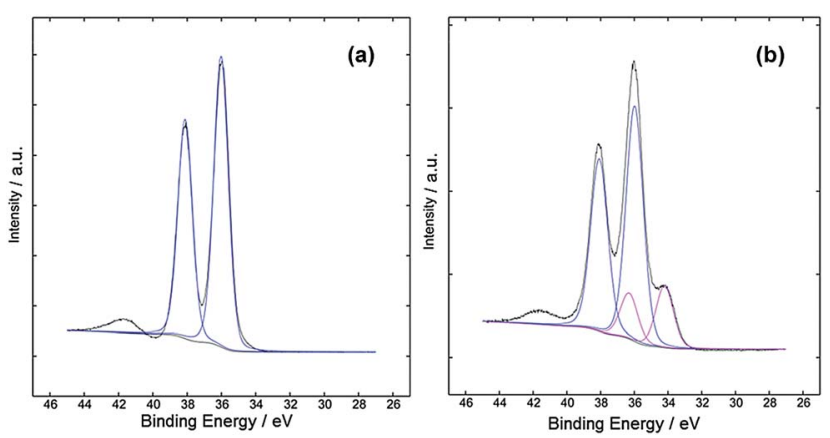

Fig. 6 XPS spectra of the W-4f orbital of the $\mathrm{Cs}_{4} \mathrm{~W}_{11} \mathrm{O}_{36}{ }^{2-}$ nanosheet coated on an Al substrate: (a) before acid treatment and (b) after acid treatment. 


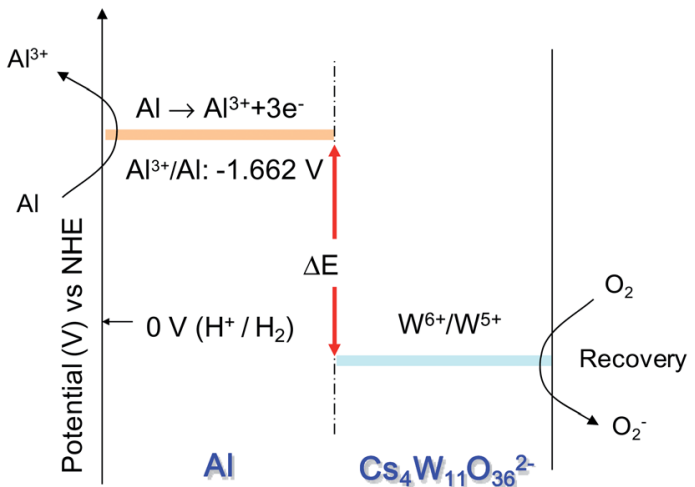

Fig. 7 The plausible scheme for the reversible color change of a thin film of $\mathrm{Cs}_{4} \mathrm{~W}_{11} \mathrm{O}_{36}{ }^{2-}$.

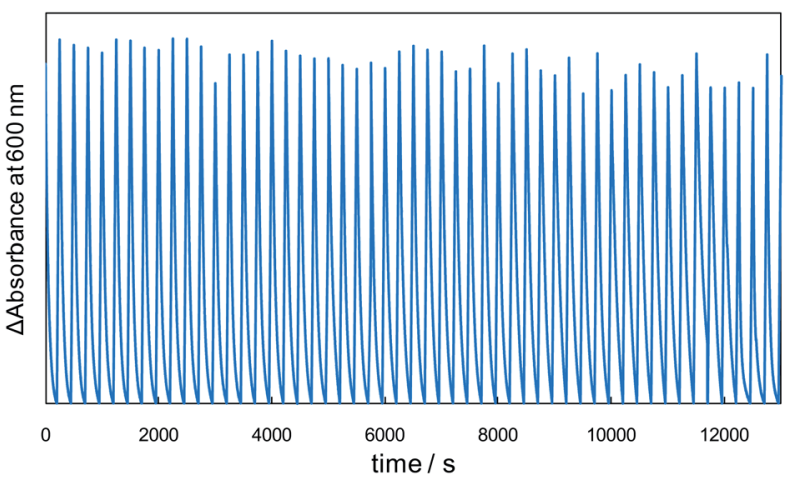

Fig. 8 Repeatability of the reversible color change in $\mathrm{Cs}_{4} \mathrm{~W}_{11} \mathrm{O}_{36}{ }^{2-}$ nanosheets/Al by acid treatment and exposure to air at room temperature.

more than 50 times. During the coloration process, the $\mathrm{Al}$ substrate was gradually dissolved, however, this dissolution of $\mathrm{Al}$ is expected to cease after the full capacity of the $\mathrm{Cs}_{4} \mathrm{~W}_{11} \mathrm{O}_{36}{ }^{2-}$ nanosheet for electrons is reached. In the present study, the $\mathrm{Cs}_{4} \mathrm{~W}_{11} \mathrm{O}_{36}{ }^{2-}$ nanosheet layer had a thickness of only $2.3 \mathrm{~nm}$, making its capacity for electrons very small. Here, we speculate on the reasonable life-time of our device based on the electrochemical point of view. We assume a reasonable carrier density in a bulk as small polarons from $10^{18}$ to $10^{20} \mathrm{~cm}^{-3}$ in tungsten oxide compounds. ${ }^{17,18}$ Under these considerations, one coloration/decoloration cycle consumes the $\mathrm{Al}$ substrate, which corresponds to the Al thickness from $0.0027 \mathrm{~nm}$ to $0.27 \mathrm{~nm}$. Therefore, the long-term durability can be expected in our chromic device, and our chromic device is very robust under repeated coloration and decoloration processes.

In addition to rapid coloration, our $\mathrm{Cs}_{4} \mathrm{~W}_{11} \mathrm{O}_{36}{ }^{2-}$ nanosheet is superior to conventional $\mathrm{WO}_{3}$ particles because of its colorlessness in the visible light range before dipping in aqueous solution. Furthermore, our $\mathrm{Cs}_{4} \mathrm{~W}_{11} \mathrm{O}_{36}{ }^{2-}$ nanosheet is very stable under alkaline conditions, whereas conventional $\mathrm{WO}_{3}$ particles are dissolved in alkaline solution. Fig. 9 shows the photos before and after dipping in aqueous solution. Our $\mathrm{Cs}_{4} \mathrm{~W}_{11} \mathrm{O}_{36}{ }^{2-}$ nanosheet exhibited reversible coloration even under alkaline conditions. And our $\mathrm{Cs}_{4} \mathrm{~W}_{11} \mathrm{O}_{36}{ }^{2-}$ nanosheet is
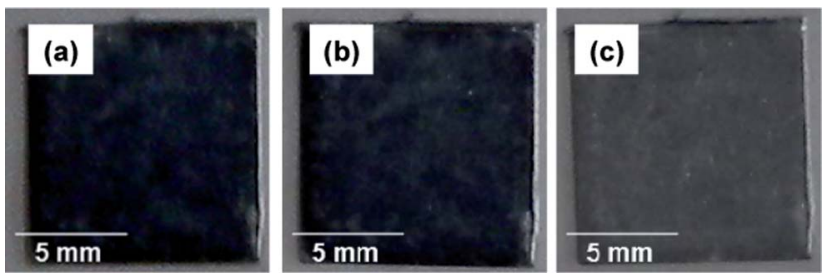

Fig. 9 Photos of $\mathrm{Cs}_{4} \mathrm{~W}_{11} \mathrm{O}_{36}{ }^{2-}$ nanosheet films after dipping in acid with $\mathrm{pH}=3$ (a), in alkaline solution with $\mathrm{pH}=11$ (b), and before coloration (c).

very stable under alkaline conditions, while conventional $\mathrm{WO}_{3}$ particles are dissolved in alkaline solution.

\section{Conclusions}

We have developed a novel, reversible chromic device consisting of a $\mathrm{Cs}_{4} \mathrm{~W}_{11} \mathrm{O}_{36}{ }^{2-}$ nanosheet film on an $\mathrm{Al}$ substrate, for which an aqueous acid solution and oxygen exposure act as the ink and eraser, respectively. The efficient coloration of this material is due to its sheet-like nanostructure. Our chromic device is comprised of non-toxic inorganic materials that are robust under heat treatment and does not require light or electric power sources, complicated sandwich cell structures, or a transparent electroconductive substrate, such as ITO or FTO glass. Hence, the chromic device described here is potentially suitable for various industrial and commercial applications, including displays, data storage devices, and sensors.

\section{Acknowledgements}

We thank Mr K. Hori at the Center for Advanced Materials Analysis, Tokyo Institute of Technology for help with TEM observations. This research was supported by the Japan Science and Technology (JST) Agency and a Precursory Research for Embryonic Science and Technology (PRESTO) Grant. We also express gratitude to Mr G. Newton for a careful reading of the manuscript.

\section{Notes and references}

1 S. K. Deb and J. L. Forrestal, in Photochromism, ed. G. H. Brown, Wiley-VCH, New York, 1971, p. 633.

2 C. G. Granquist, Handbook of Inorganic Electrochromic Materials, Elsevier, Amsterdam, 1995.

3 R. J. Colton, A. M. Guzman and J. W. Rabalais, Acc. Chem. Res., 1978, 11, 170.

4 B. W. Faughnan and R. S. Crandall, Top. Appl. Phys., 1980, 40, 181.

5 C. S. Blackman and I. P. Parkin, Chem. Mater., 2005, 17, 1583.

6 C. Bechinger, E. Wirth and P. Ledierer, Appl. Phys. Lett., 1996, 68, 2834.

7 C. M. Lampert, Sol. Energy Mater., 1984, 11, 1.

8 P. Delichere, P. Falaras, M. Froment, H. L. Goff and B. Agius, Thin Solid Films, 1988, 161, 35.

9 Z. G. Zhao, Z. F. Liu and M. Miyauchi, Adv. Funct. Mater., 2010, 20, 4162. 
10 M. Miyauchi, Y. Li, S. Yanai and K. Yotsugi, Chem. Commun., 2011, 47, 8596.

11 M. S. Paley, E. J. Meehan, C. D. Smith, F. E. Rosenberger, S. C. Howard and J. M. Harris, J. Org. Chem., 1989, 54, 3432.

12 K. Fukuda, K. Akatsuka, Y. Ebina, R. Ma, K. Takada, I. Nakai and T. Sasaki, ACS Nano, 2008, 2, 1689.

13 Z. Liu, Z. Zhao and M. Miyauchi, J. Phys. Chem. C, 2009, 113, 17132.
14 Q. Zhong and K. Colbow, Thin Solid Films, 1991, 205, 85.

15 E. Kikuchi, N. Hirota, A. Fujishima, K. Itoh and M. Murabayashi, J. Electroanal. Chem., 1995, 381, 15.

16 J. Hou, G. Zuo, G. Shen, H. Guo, H. Liu, P. Chen, J. Zhang and S. Guo, Nanoscale Res. Lett., 2009, 4, 1241.

17 E. Salje, J. Appl. Crystallogr., 1974, 7, 615.

18 J. Ederth, A. Hogel, G. A. Niklasson and C. G. Granqvist, J. Appl. Phys., 2004, 96, 5722. 